\title{
Электрическая активность протяженных дефектов в мультикремнии
}

\author{
(C) С.М. Пещерова ${ }^{1}$, Е.Б. Якимов ${ }^{2}$, А.И. Непомнящих ${ }^{1}$, Л.А. Павлова ${ }^{1}$, О.В. Феклисова ${ }^{2}$, Р.В. Пресняков ${ }^{1}$ \\ ${ }^{1}$ Институт геохимии им. А.П. Виноградова Сибирского отделения Российской академии наук, \\ 664033 Иркутск, Россия \\ ${ }^{2}$ Институт проблем технологии микроэлектроники и особочистых материалов Российской академии наук, \\ 142432 Черноголовка, Россия \\ E-mail: spescherova@mail.ru
}

(Получена 9 февраля 2017 г. Принята к печати 16 февраля 2017 г.)

\begin{abstract}
Проведены исследования по распределению времени жизни неравновесных носителей заряда $(\tau)$ в мультикристаллическом кремнии (мультикремнии), выращенном методом Бриджмена из высокочистого рафинированного металлургического кремния. Выявлены закономерности изменения $\tau$, обусловленные особенностями зеренно-граничной структуры слитков. Границы зерен, дислокации и примесные микровключения исследовали методами рентгеноспектрального электронно-зондового микроанализа (РСМА/ЕРМА) и электронной микроскопии (PЭM/SEM) с применением селективного кислотного травления. Электрическую активность протяженных дефектов регистрировали методом наведенного тока (HT/EBIC).
\end{abstract}

DOI: 10.21883/FTP.2018.02.45454.8546

\section{1. Введение}

Основными параметрами мультикристаллического кремния (мультикремния) для солнечной энергетики, используемыми для оценки его качества, являются электрофизические характеристики (удельное электрическое сопротивление, время жизни неравновесных носителей заряда) и параметры макроструктуры, где немаловажную роль играют количество границ зерен в единице объема слитка и их типы, а также ориентация кристаллитов. Считается, что столбчатый рост кристаллитов и формирование крупноблочной структуры происходят вследствие реализации условий плоского фронта кристаллизации (метод Бриджмена). Достижение электрофизических характеристик мультикремния, соответствующих требованиям солнечной энергетики, возможно при использовании исходного кремния с долей основного вещества от 99.99 до 99.999 ат\%. В этом случае концентрации примесей в слитке будут на уровне пределов их растворимости в кремнии и ниже [1]. Установленные нами ранее особенности получения мультикристаллического кремния из металлургического кремния высокой чистоты показали, что нарушения столбчатого роста кремния связаны с переходом к вогнутой форме фронта кристаллизации [2]. Это также приводит к возникновению дополнительных дефектов (дислокации, специальные границы и др.), которые, в свою очередь, оказывают влияние на распределение времени жизни неравновесных носителей заряда [3]. Электрическая активность специальных границ зерен зависит не только от структуры границ, но и от процессов геттерирования примесей на них и ретикулярной плотности содержащих их материнских зерен [4-7]. Настоящая статья посвящена исследованию взаимосвязи электрической активности протяженных дефектов с пространственным распределением времени жизни неравновесных носителей заряда (НН3).

\section{2. Материалы и методы исследования}

В данной работе объектами исследования были блоки мультикремния, выращенные методом Бриджмена из высокочистого металлургического кремния (чистота $>99.99 \%$ ). При соблюдении одинаковых условий кристаллизации слитков Крс1, Крс2, Крс3 и Крс4 (скорость перемещения тигля $0.5 \mathrm{~cm} /$, скорость вращения тигля 1 об/мин) варьировалось содержание примесей в исходном металлургическом кремнии. Исходные составы, приведенные в табл. 1, определялись методом масс-спектрометрии с индуктивно связанной плазмой (ИСП-МС) [2].

Измерения эффективного времени жизни ННЗ в образцах мультикремния проводились на установке „Тауметр-2М“ бесконтактным СВЧ резонаторным методом по кривой затухания фотопроводимости. Объемную генерацию фотоносителей осуществляли воздействием на образец импульсным лазерным излучением с длиной волны $\lambda=1.06$ мкм с коэффициентом поглощения в кремнии $\alpha \approx 10-15 \mathrm{~cm}^{-1}$. В расчете объемного времени жизни мы учитывали диффузионную составляющую поверхностной рекомбинации. Измерения эффективного времени жизни НHЗ $\tau$ выполнялись по стандарту SEMI MF 1535. При этом уровень начальной точки на кривой затухания составлял 0.7 сигнала фотопроводимости, уровень конечной точки $-0.7 / e$ сигнала фотопроводимости. Тип проводимости определяли методом выпрямления тока точечным контактом металл-полупроводник, удельное электрическое сопротивление измеряли четырехзондовым методом на установке „Рометр“.

В нижней и верхней частях каждого слитка (2 см от основания и 2 см от вершины соответственно) перпендикулярно оси роста были вырезаны пластинки размером $8 \times 6 \times 2$ мм, на которых проводили замеры времени жизни ННЗ в последовательно расположенных областях поверхности образца размером $2 \times 2$ мм, соизмеримым с диаметром светового пятна 2 мм. Для определения ско- 
Таблица 1. Содержание (ppm) основных примесей в исходных составах шихты для выращивания кристаллов мультикремния

\begin{tabular}{c|c|c|c|c|c|c|c|c|c|c|c|c|c}
\hline Слиток & $\mathrm{B}$ & $\mathrm{P}$ & $\mathrm{Al}$ & $\mathrm{Ca}$ & $\mathrm{Mg}$ & $\mathrm{Ti}$ & $\mathrm{V}$ & $\mathrm{Cr}$ & $\mathrm{Mn}$ & $\mathrm{Fe}$ & $\mathrm{Co}$ & $\mathrm{Ni}$ & $\mathrm{Zr}$ \\
\hline Крс1 & 0.62 & 0.55 & 0.97 & 0.16 & 0.25 & 0.76 & 0.66 & 0.09 & 0.1 & 5.36 & 0.44 & 0.07 & 0.34 \\
Крс2 & 0.21 & 0.18 & 0.32 & 0.05 & 0.08 & 0.26 & 0.22 & 0.03 & 0.03 & 1.79 & 0.15 & 0.02 & 0.11 \\
Крс3 & 0.03 & 0.026 & 0.015 & 0.008 & 0.012 & 0.036 & 0.031 & 0.004 & 0.005 & 0.26 & 0.021 & 0.003 & 0.016 \\
Крс4 & 0.21 & 0.18 & 0.45 & 0.24 & 0.3 & 0.38 & 0.3 & 0.014 & 0.04 & 6.12 & 0.17 & 0.1 & 0.12
\end{tabular}

рости рекомбинации неравновесных носителей заряда методом наведенного тока, индуцированного электронами (ЕВIC), образцы химически полировали в растворе кислот $\mathrm{HF}$ и $\mathrm{HNO}_{3}$, затем напыляли $\mathrm{Al}$ для создания барьеров Шоттки, омические контакты формировали на обратной стороне путем втирания пасты Al-Ga. После измерений наведенного тока напыленный слой удаляли в растворе $\mathrm{HF}: \mathrm{H}_{2} \mathrm{O}$, затем механически полировали поверхность образцов с последующим применением селективного травителя Дэша $\left(\mathrm{HF}: \mathrm{HNO}_{3}: \mathrm{CH}_{3} \mathrm{COOH}\right)$ для исследования структуры поверхности образцов в режиме растрового электронного микроскопа (РЭМ) на микроанализаторе JXA8200 (JEOL).

\section{3. Результаты и их обсуждение}

Вдоль оси роста по всей высоте слитков (10.5 см) определяли электрофизические параметры, такие как тип проводимости, удельное электрическое сопротивление $(\rho)$ и время жизни НН3 $(\tau)$. Кристаллы Крс1, Крс2 и Крс4 имели $p$-тип проводимости, кристалл Крс3 - n-тип. Полученные данные представлены в табл. 2.

Как видно из данных табл. 2, характер распределения значений удельного сопротивления и $\tau$ ННЗ в слитках заметно различается: если величина $\rho$ плавно варьируется по высоте всех исследуемых кристаллов, то значение $\tau$ претерпевает резкие изменения. Особенно хорошо это заметно в образце Крс3, где наблюдаются самые высокие усредненные значения $\rho$ и $\tau$. Среди оставшихся кристаллов наибольшие усредненные значения $\rho$ наблюдаются в Крс4, а $\tau-$ в Крс2. Особый интерес представляли факторы, ответственные за характер распределения значений $\tau$ в кристаллах. Поэтому были осуществлены дальнейшие измерения по поверхности образцов, вырезанных из нижней $(\mathrm{H})$ и верхней $(\mathrm{B})$ частей каждого слитка. На рис. 1 приведено схематическое
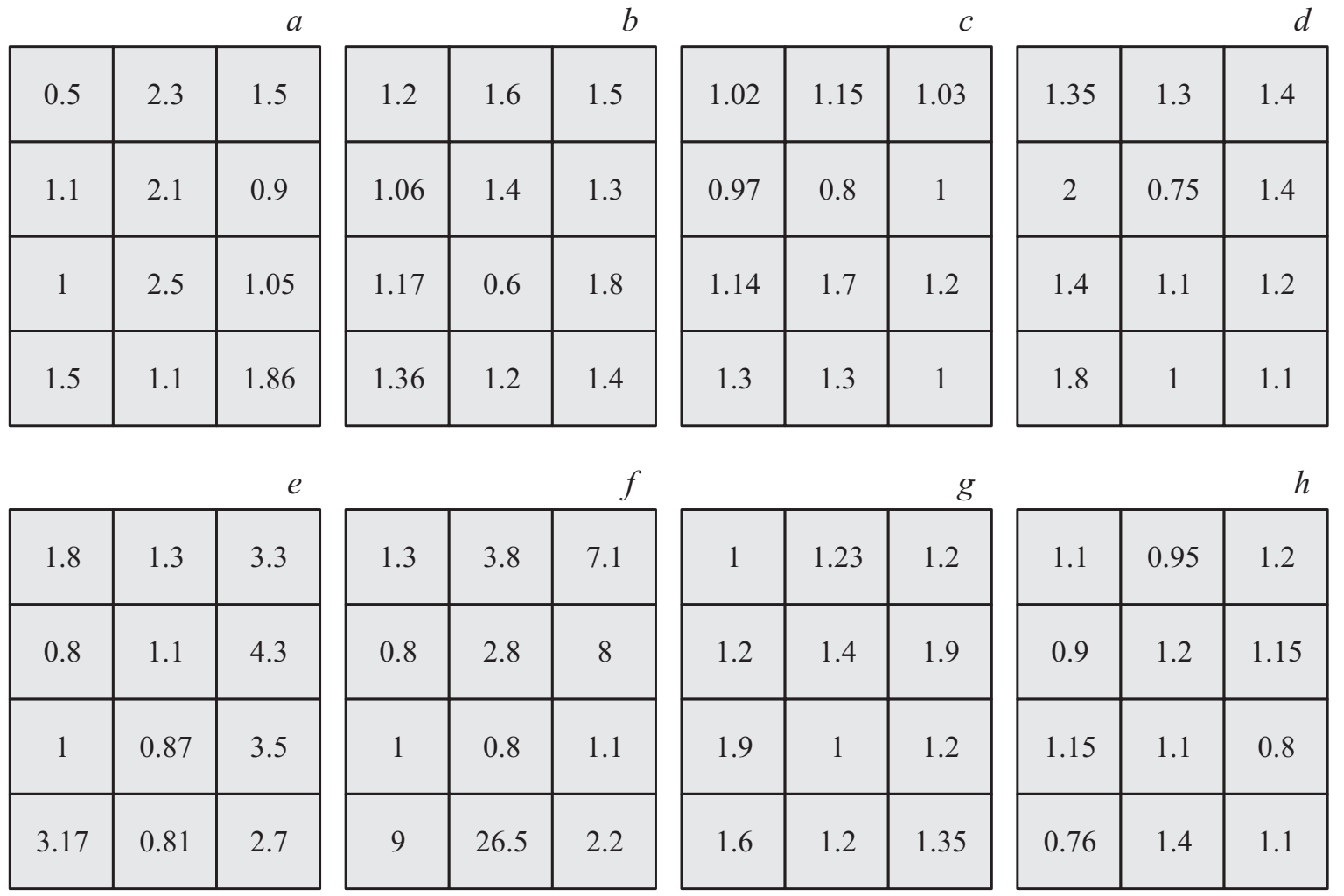

\begin{tabular}{|l|l|l|}
\hline \multicolumn{1}{c}{} & \multicolumn{2}{c}{} \\
\hline 1.1 & 0.95 & 1.2 \\
\hline 0.9 & 1.2 & 1.15 \\
\hline 1.15 & 1.1 & 0.8 \\
\hline 0.76 & 1.4 & 1.1 \\
\hline
\end{tabular}

Рис. 1. Карты распределения $\tau$ ННЗ (в мкс) по поверхности образцов, перпендикулярной оси роста слитков мультикремния. Образцы: $a-\mathrm{Kpc1(H),} b-\mathrm{Kpc1(B),} c-\mathrm{Kpc} 2(\mathrm{H}), d-\mathrm{Kpc} 2(\mathrm{~B}), e-\mathrm{Kpc} 3(\mathrm{H}), f-\mathrm{Kpc} 3(\mathrm{~B}), g-\mathrm{Kpc} 4(\mathrm{H}), h-\mathrm{Kpc} 4(\mathrm{~B})$. 
Таблица 2. Электрофизические параметры слитков мультикремния, измеренные вдоль оси роста по высоте $F$ от нижнего края слитка

\begin{tabular}{|c|c|c|c|c|c|c|c|c|c|c|c|c|}
\hline \multicolumn{2}{|c|}{$F$, см } & 0.5 & 0.15 & 0.25 & 0.35 & 0.45 & 0.55 & 0.65 & 0.75 & 0.85 & 0.95 & Среднее значение \\
\hline \multirow{2}{*}{ Kpc1 } & $\rho, \mathrm{OM} \cdot \mathrm{cm}$ & 0.23 & 0.22 & 0.22 & 0.22 & 0.22 & 0.26 & 0.23 & 0.19 & 0.18 & 0.17 & 0.21 \\
\hline & $\tau$, мкс & 2.53 & 2.06 & 2 & 2.23 & 2.03 & 2.2 & 2.6 & 1.93 & 1.93 & 2.03 & 2.15 \\
\hline \multirow{2}{*}{ Крс2 } & $\rho, \mathrm{OM} \cdot \mathrm{cm}$ & 0.67 & 0.66 & 0.66 & 0.65 & 0.63 & 0.6 & 0.56 & 0.53 & 0.5 & 0.46 & 0.59 \\
\hline & $\tau$, мкс & 3.1 & 2.7 & 3.5 & 3.4 & 3.2 & 3.1 & 2.4 & 2.4 & 2.3 & 3.1 & 2.92 \\
\hline \multirow{2}{*}{ Крс3 } & $\rho, \mathrm{OM} \cdot \mathrm{cm}$ & 1.6 & 1.7 & 1.8 & 1.8 & 1.73 & 1.67 & 1.62 & 1.79 & 2.25 & 2.61 & 1.85 \\
\hline & $\tau$, мкс & 3.8 & 3.7 & 3.5 & 4 & 5.3 & 44 & 19.3 & 12.9 & 9.26 & 6.73 & 11.25 \\
\hline \multirow{2}{*}{ Крс4 } & $\rho, \mathrm{OM} \cdot \mathrm{cm}$ & 0.8 & 0.77 & 0.72 & 0.7 & 0.68 & 0.66 & 0.64 & 0.62 & 0.6 & 0.55 & 0.67 \\
\hline & $\tau$, мкс & 1.17 & 0.8 & 0.9 & 1.17 & 0.96 & 0.92 & 0.93 & 0.73 & 1.15 & 1.12 & 0.98 \\
\hline
\end{tabular}

изображение областей измерения $\tau$ ННЗ на поверхности образцов Крс1, Крс2, Крс3 и Крс4.

Для дальнейших исследований были выбраны образцы Крс2(В) и Крс3(В) с более высокими значениями $\tau$ НН3. Помимо этого, в образце Крс3(В) были зарегистрированы аномально высокие значения $\tau$ НН3 (26.5 и 9 мкс) на двух соседних участках образца (рис. 1). Для установления взаимосвязей между параметрами $\tau$ и макроструктурой мультикремния были проведены исследования поверхности с использованием РЭМ. На рис. 2 представлены РЭМ-изображения поверхности образцов Крс2(В) и Крс3(В), составленные из фрагментов, про- нумерованных нами в виде матрицы, полученные в обратно-рассеянных электронах (BEI).

Как видно из рис. 2, макроструктура исследуемых образцов существенно различается. Если для Крс2(В), как и для всего слитка в целом, характерными являются мелкозернистая структура с прямолинейными, преимущественно параллельными относительно друг друга границами (рис. 2,a), то Крс3 (рис. 2,b) обладает крупноблочной, столбчатой структурой зерен с изогнутыми границами. На рис. 2 поверхности образцов разделены на сектора, каждый из которых соответствует определенному значению $\tau$ ННЗ (мкс). Наиболее высокие

$a$
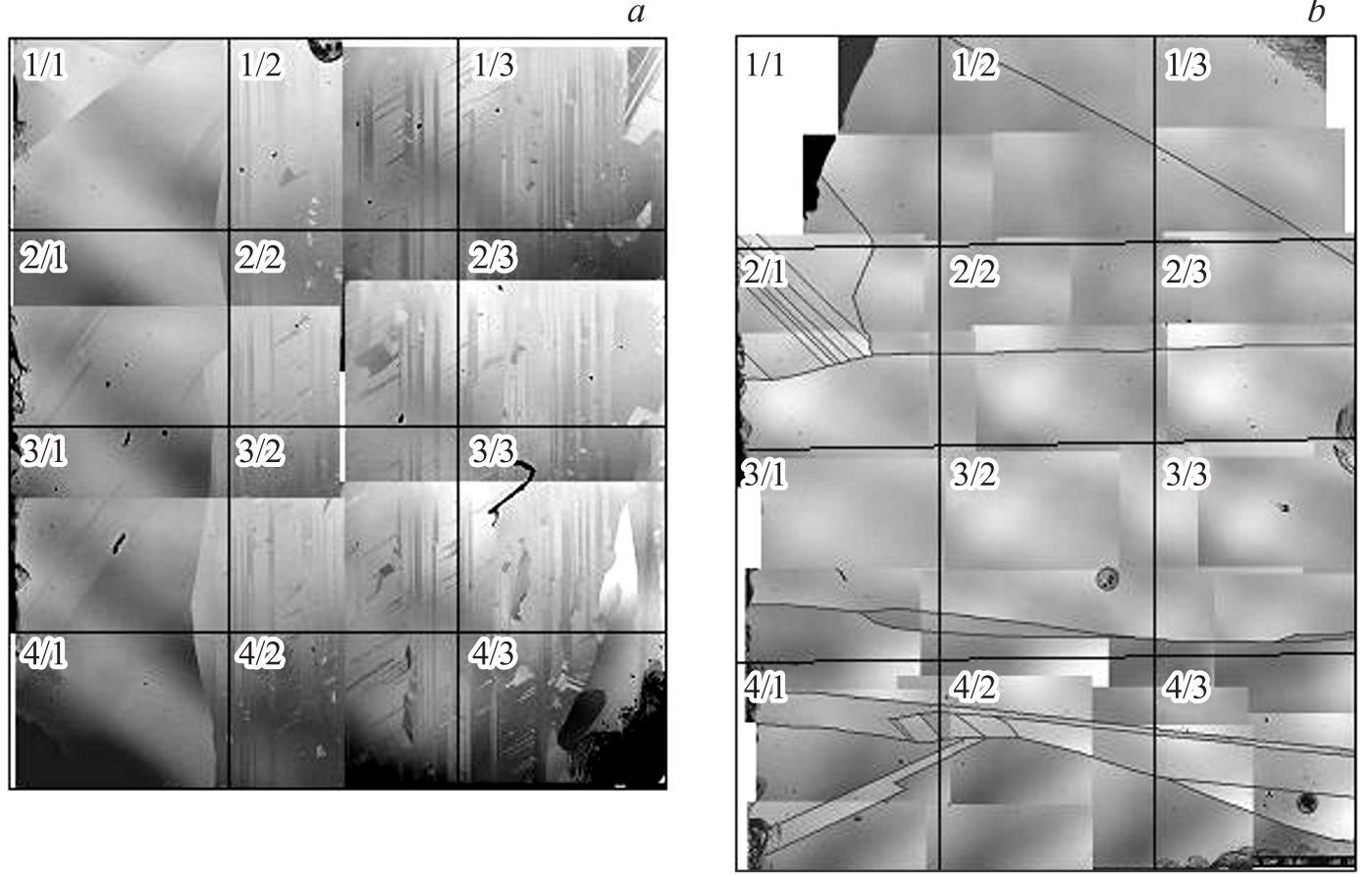

Рис. 2. РЭМ-изображения полированной поверхности образцов в обратно-рассеянных электронах (ВЕІ), составленные из фрагментов: $a-$ Крс2(В), увеличение $\times 60 ; b-$ Крс3(В), увеличение $\times 40$. 


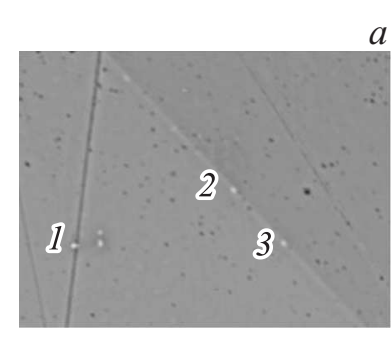

$10 \mu \mathrm{m}$

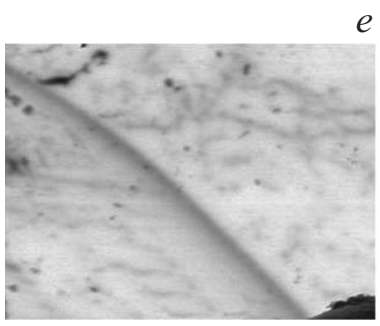

$100 \mu \mathrm{m}$
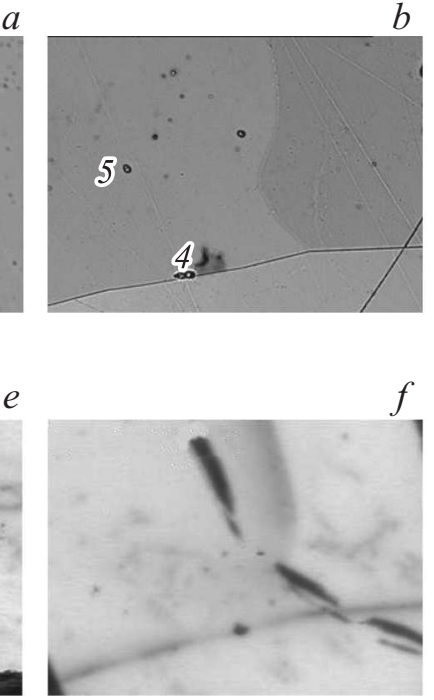

$100 \mu \mathrm{m}$

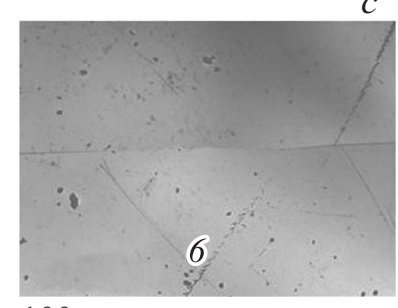

$100 \mu \mathrm{m}$

$f$

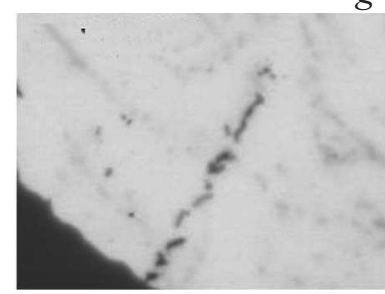

$100 \mu \mathrm{m}$

$g$

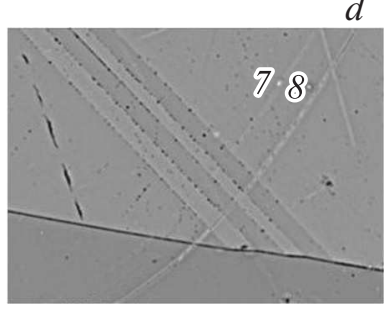

$10 \mu \mathrm{m}$

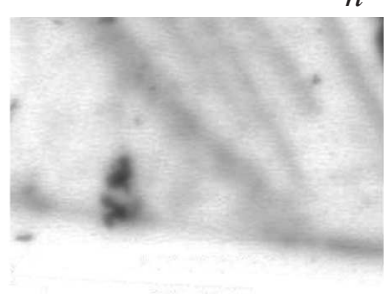

$100 \mu \mathrm{m}$

Рис. 3. Изображения секторов: $a, b, c, d-$ РЭМ изображения (BЕI) травленой поверхности фрагментов секторов Крс3(В) 1/1, 2/1, $3 / 2$ и 4/1 соответственно (1-8- микровключения); $e, f, g, h-$ ЕВІС-изображения фрагментов секторов $1 / 1,2 / 1,2 / 2$ и 4/1.

значения $\tau$ ННЗ в Крс2(В) (см. рис. $1, b)$ соответствуют секторам 1/1 (1.35 мкс), 2/1 (2 мкс), 3/1 (1.4 мкс), 4/1 (1.8 мкс) с крупнозернистой структурой и минимальным количеством изогнутых границ (области секторов 2/1 и 3/1 содержат субзерна с двойниковыми границами. В Крс3(В) высокие значения $\tau$ относятся к секторам 1/3 (7.1 мкс), 2/3 (8 мкс), 4/1 (9 мкс) и 4/2 (26.5 мкс), в которых содержатся границы зерен, тогда как в секторах с наименьшими значениями $\tau$ (сектора $3 / 2$ и $3 / 3$ ) границы отсутствуют. Для установления основных причин снижения параметра $\tau$ были проведены исследования пространственного распределения электрической активности по всей площади поверхности образцов Крс2(В) и Крс3(В). Затем образцы подвергались селективному химическому травлению для выявления тонкой структуры поверхности и электрически активных дефектов. Полученные результаты отображены на рис. 3 .

Межзеренная граница из сектора $1 / 1$, как видно на изображении (рис. $3, a, e$ ), является электрически активной и после травления представляет собой выпуклую линию, вдоль которой располагаются микровключения $(1-3$ на рис. $3, a)$ и ямки травления. При этом, если ямки травления с одинаковой вероятностью встречаются как в плоскости границы, так и в зерне, то микровключения располагаются преимущественно по линии границы. В секторе 2/1 микровключения являются электрически активными дефектами и присутствуют как на границе $(4$ на рис. $3, b)$, так и в зерне $(5$ на рис. $3, b)$. Полоса из дислокационных ямок травления в секторе $3 / 2$ проявляет выраженную электрическую активность и содержит микровключения ( 6 на рис. $3, c, g)$. Несмотря на то что границы в секторе 4/1 частично или целиком проявляют электрическую активность, значение $\tau$ в данном секторе является высоким по сравнению с секторами 1/1, 2/1 и 3/2. Наибольший контраст EBIC в данном секторе проявляют специальные границы с повышенным содержанием ямок травления по сравнению с близлежащими областями зерен (рис. $3, d, h$ ). Составы микровключений 1-8 на рис. 3 представлены в табл. 3.

Практически все микровключения являются электрически активными независимо от их месторасположения. Характерными особенностями являются малый размер (диаметр не более 0.5 мкм) и сферичная форма. Наиболее вероятно, что все это микровключения вторичного типа, они формируются в пограничном кристаллическом слое мультикремния, локализуясь на протяженных микродефектах структуры (дислокации, границы зерен). Так, микровключения $2,3,4$ (рис. $3, a, b)$ располагаются на

Таблица 3. Элементный состав точек, отмеченных на рис. 3 как микровключения в Крс3(В)

\begin{tabular}{|c|c|c|c|c|c|c|c|c|c|c|}
\hline № & $\mathrm{Si}$ & $\mathrm{O}$ & $\mathrm{C}$ & $\mathrm{Al}$ & $\mathrm{Na}$ & $\mathrm{Mg}$ & $\mathrm{Ca}$ & $\mathrm{Cr}$ & $\mathrm{Cu}$ & $\mathrm{Zn}$ \\
\hline 1 & 100.0 & н.о. & H.O. & H.о. & $<0.1$ & н.о. & H.O. & н.о. & H.о. & H.о. \\
\hline 2 & 99.9 & H.O & H. & $<0.1$ & H.O. & $<0.1$ & H.O. & н.о. & H.O. & H.O. \\
\hline 3 & 99.9 & H.O & H.O. & H.О. & $<0.1$ & $<0.1$ & H.O. & H.о. & H.O. & H.O. \\
\hline 4 & 85.8 & 13.1 & H.O. & 1.082 & H.о. & H.O. & H.O. & H.o. & H.O. & H.O. \\
\hline 5 & 59.4 & 29.2 & H.о. & H.о. & H.O. & н.о. & 11.4 & н.о. & н.о. & н.о. \\
\hline 6 & 20.6 & 22.7 & 23.3 & H.о. & H.о. & H.о. & H.O. & 33.4 & H.O. & o. \\
\hline 7 & H.О. & H.o. & H.O. & H.О. & H.O. & н.о. & H.O. & H.o. & 60.5 & 39.5 \\
\hline 8 & 99.9 & H.о. & H.O. & н.о. & $<0.1$ & H.о. & H.O. & н.о. & H.O. & H.O. \\
\hline
\end{tabular}

Примечание. № - номер микровключения. Определение состава выполнено на микроанализаторе JXA8200 с помощью энергодисперсионного спектрометра EX-84055MU (JEOL Ltd, Япония). Приведено содержание элементов в массовых \%; н.о. - не обнаружено. 

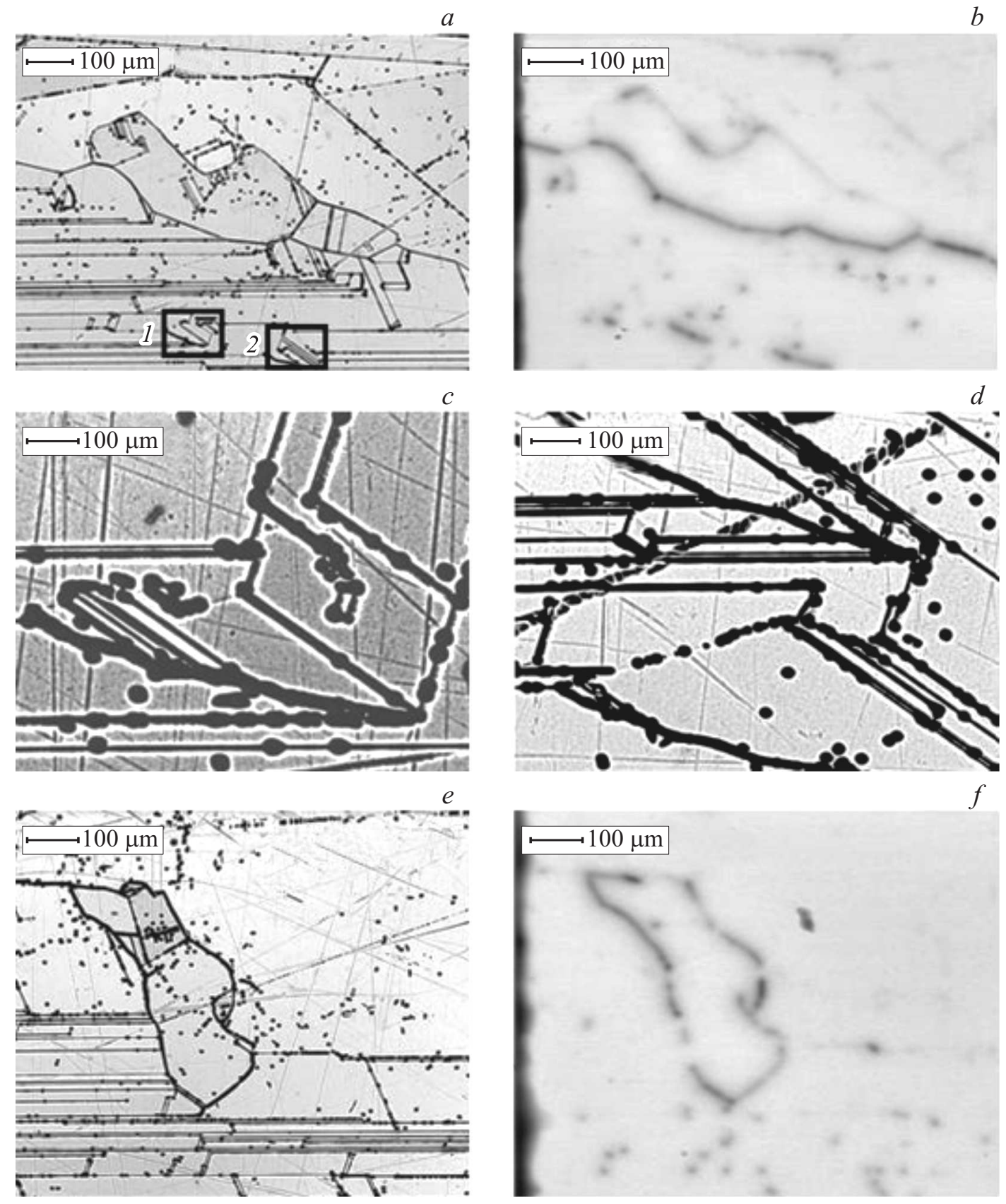

Рис. 4. $a$ - РЭМ-изображение (BЕI) травленой поверхности фрагмента сектора $1 / 3$ Крс2(В); $b-$ ЕВІС-изображение поверхности сектора $1 / 3 \mathrm{Kpc2(B);} c, d-$ РЭМ-изображение травленой поверхности выделенных на $(a)$ фрагментов 1 и 2 соответственно; $e-$ РЭМ-изображение (ВЕI) травленой поверхности сектора 2/3 Крс2(В), $f$ - ЕВІС-изображение поверхности сектора 2/3 Крс2(В).

границах зерен и локально усиливают их электрическую активность, тем самым существенно снижая среднее значение $\tau$ в данном секторе. Микровключения $1,5,7$ и 8 (рис. $3, a, b, d$ ) располагаются в областях зерен и в сочетании с дефектами структуры (судя по ямкам травления, характерным для дислокаций) оказывают не менее сильное влияние на снижение $\tau$ ННЗ, чем микровключения на границах зерен.

На рис. 3, $h$ изображен фрагмент сектора 4/1 Крс3(В) с границами двойникования, вдоль которых располага- ются множество дислокационных ямок травления. Эти границы проявляют более низкую электрическую активность, и значение $\tau$ в данном секторе на порядок выше, чем в секторах 2/1 и 3/2. Вероятно, это связано с отсутствием микровключений в области границ зерен.

Интересным является тот факт, что исходное содержание примесей в шихте (за исключением Al см. табл. 1) Крс3 в $(6.7 \pm 0.7)$ раз меньше, чем в Крс2. При этом Крс3 имеет $n$-тип проводимости в отличие от остальных кристаллов. Следует отметить, 
что единый режим травления по-разному повлиял на состояние поверхности образцов Крс2(В) и Крс3(В): на поверхности образца Крс2 микровключения не были обнаружены (рис. 4).

Как видно по результатам исследований методом EBIC поверхности Крс2(В), лишь малая часть межзеренных границ являются электрически активными (рис. $4, b, f)$. Если учесть, что на изображениях данных фрагментов наблюдается множество межзеренных границ, электрическую активность проявляют только границы определенного вида (они имеют изогнутые контуры и в них наблюдается высокое содержание ямок травления, а также отчетливо видны отличия их строения от соседних, электрически неактивных границ). Изогнутые границы являются границами со случайной ориентацией, и их контраст всегда больше, чем контраст специальных границ.

\section{4. Заключение}

Результаты исследований пространственного распределения рекомбинационной активности границ зерен и протяженных дефектов в мультикремнии показали, что для достижения оптимальных электрофизических характеристик данного материала недостаточно руководствоваться одними параметрами макроструктуры, такими как плотность границ зерен на единицу объема слитка или направленность кристаллитов. Важную роль в процессах формирования макро- и микроструктуры играют присутствующие в исходном металлургическом кремнии примеси. В зависимости от их концентрации и соотношений элементов происходит формирование микровключений определенных типов и составов. Установлено, что вторичные микровключения оказывают существенное влияние на рекомбинационную активность дефектов структуры (дислокаций, границ зерен) и в большей степени ответственны за снижение объемных электрофизических характеристик мультикремния, чем дефекты с более высокой плотностью распределения без микровключений.

Работа выполнена при поддержке гранта РФФИ № 16-35-00140-мол_а с использованием научного оборудования ЦКП „Изотопно-геохимических исследований“ ИГХ СО РАН.

\section{Список литературы}

[1] Б.Г. Грибов, К.В. Зиновьев. Неорг. матер., 39 (7), 775 (2003).

[2] А.И. Непомнящих, Р.В. Пресняков, И.А. Елисеев, Ю.В. Сокольникова. Письма ЖТФ, 37 (15), 103 (2011).

[3] С.М. Пещерова, А.И. Непомнящих, Л.А. Павлова, И.А. Елисеев, Р.В. Пресняков. ФТП, 48 (4), 492 (2014).

[4] С.М. Пещерова, А.И. Непомнящих, Л.А. Павлова. Письма ЖТФ, 40 (22), 30 (2014).

[5] С.М. Пещерова, Е.Б. Якимов, А.И. Непомнящих, Л.А. Павлова, О.В. Феклисова. ФТП, 49 (6), 741 (2015).
[6] S. Tsurekawa, K. Kido, T. Watanabe. Mater. Sci. Eng. A, 462, 61 (2007).

[7] J. Chen, T. Sekiguchi, D. Yang, F. Yin, K. Kido, S. Tsurekawa. J. Appl. Phys., 96, 5490 (2004).

Редактор Л.В. Шаронова

\section{Electrical activity of extended defects in multicrystalline silicon}

\author{
S.M. Pescherova ${ }^{1}$, E.B. Yakimov ${ }^{2}$, \\ A.I. Nepomnyashchikh' ${ }^{1}$, L.A. Pavlova ${ }^{1}$, \\ O.V. Feklisova ${ }^{2}$, R.V. Presnyakov ${ }^{1}$ \\ ${ }^{1}$ Vinogradov Institute of Geochemistry, \\ Siberian Branch of Russian Academy of Sciences, \\ 664033 Irkutsk, Russia \\ ${ }^{2}$ Institute of Microelectronics Technology \\ and High Purity Materials, \\ Russian Academy of Sciences, \\ 142432 Chernogolovka, Russia
}

\begin{abstract}
Minority carrier lifetime distribution in multicrystalline silicon, grown by the Bridgman technique from upgraded metallurgical silicon (UMG-Si) is investigated. Regularities of minority carrier lifetime variation dependences on the structure of grains and grain boundaries are developed. The grain boundaries, dislocations and impurity micro inclusions were studied by electron-probe microanalysis, scanning electron microscopy after selective chemical etching. The electric activity of extended defects was characterized by measuring the electron-beam-induced current.
\end{abstract}

